\title{
Efeito da oxigenação por agitação manual da água na eficiência de inativação de coliformes termotolerantes utilizando luz solar para desinfecção em batelada
}

\section{Effect of oxygenation by manual agitation of water on inactivation efficiency of thermotolerant coliforms using solar light batch disinfection}

\author{
Márcio Pessoa Botto \\ Engenheiro Civil pela Universidade Federal do Ceará (UFC). Mestre em Saneamento Ambiental. Doutorando em Saneamento Ambiental pelo Departamento de \\ Engenharia Hidráulica e Ambiental (DEHA) da UFC
}

Francisco Suetônio Bastos Mota

Doutor em Saúde Ambiental pela Universidade de São Paulo (USP). Professor Titular do DEHA/UFC. Membro da Academia Cearense de Ciências

Beatriz Susana Ovruski de Ceballos

Doutora em Ciências Biológicas (Microbiologia) pela USP. Professora Titular do Departamento de Biologia do CCBS Centro de Ciências Biológicas e da

Saúde (CCBS) da Universidade Federal da Paraíba (UFPB)

\section{Resumo}

Foi avaliado o efeito da agitação manual de amostras de água submetidas à desinfecção solar na eficiência de inativação de coliformes termotolerantes. Garrafas com agitação prévia e sem agitação foram expostas à radiação solar no horário das 9h às 15h (seis horas no total) e analisados o teor de oxigênio dissolvido (OD) e concentração de coliformes termotolerantes de hora em hora. A desinfecção com luz solar mostrou-se capaz de melhorar a qualidade sanitária da água

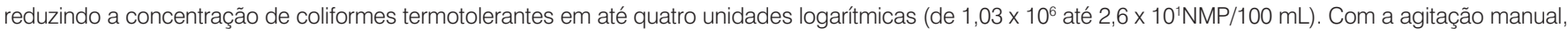
houve oxigenação considerável nas amostras de água (máxima concentração de OD de 6,61 mg/L nas amostras de águas agitadas e de 5,56 mg/L nas amostras sem agitação), porém o aumento de OD na água não teve efeito significativo sobre a inativação dos coliformes termotolerantes $(p>0,05)$.

Palavras-chave: decaimento bacteriano; garrafas PET; radiação solar; oxigênio dissolvido.

\section{Abstract}

This study aimed at evaluating the manual agitation effect on inactivation efficiency of thermotolerant coliforms of water bottles submitted to solar disinfection. Agitated bottles and non-agitated bottles were exposed to sunlight from 9:00 a.m. to 3:00 p.m. Dissolved oxygen (DO) and thermotolerant coliforms concentrations were analyzed hourly. The solar disinfection improved the water quality, reducing thermotolerant coliforms concentration by 4 logs (from $1.0 \times 10^{6}$ to $2.6 \times$ $10^{1} \mathrm{MPN} / 100 \mathrm{~mL}$ ). With the manual agitation, there was considerable oxygenation in the water samples (maximum of $6.61 \mathrm{mg} / \mathrm{L}$ in samples with manual agitation and of $5.56 \mathrm{mg} / \mathrm{L}$ for those without agitation), but the increase in DO had no significant effect on the inactivation of thermotolerant coliforms ( $p>0.05$ ).

Keywords: bacterial decay; PET bottles; solar radiation; dissolved oxygen.

\section{Introdução}

Apesar dos esforços realizados nas décadas de 1980 e 1990 para prover condições adequadas de saneamento, hoje cerca de 1,1 bilhão de pessoas ainda não possuem acesso a abastecimento de água de boa qualidade (WHO/UNICEF, 2000).

O fornecimento de água potável para populações rurais é um desafio econômico e tecnológico. Na sede dos municípios onde não há abastecimento de água por rede geral, as prefeituras 
Para essas populações, é importante dispor de tecnologias inovadoras apropriadas, simples e de baixo custo, que possam ser geridas e sustentadas a partir de recursos locais para que sejam bem aceitas pela população e que se tornem barreiras sanitárias incorporadas nos hábitos diários (WEGELIN et al, 1994).

A desinfecção é uma poderosa barreira sanitária que pode garantir água de excelente qualidade microbiológica para consumo humano. A desinfecção de água com luz solar vem sendo aplicada em países em desenvolvimento como uma técnica segura para o tratamento da água. O método SODIS, sigla para solar disinfection, é um método em batelada, simples e barato, que dispensa o fornecimento de energia elétrica e utiliza apenas garrafas tipo PET (Polietileno tereftalato) e o sol, universalmente disponível e gratuito.

Vários estudos (ACRA; RAFFOUL; KARAHAGOPIAN, 1984; WEGELIN et al, 1994; SOMMER et al, 1997; REED, 1997) apontam a eficiência do método, com inativação de 99,9\% de coliformes termotolerantes durante tempo médio de cinco horas de exposição ao sol. Essa eficiência, segundo os autores, depende das condições de insolação local, grau de nebulosidade, qualidade da água (turbidez e cor), tipo de recipiente a ser utilizado, espessura da lâmina d'água, condição de aerobiose e superfície suporte para exposição ao sol. A maior desvantagem dessa técnica é a ausência de residual desinfetante na água, o que pode permitir a recontaminação da água, dependendo das condições de armazenamento e higiene domiciliar.

O requisito básico para a desinfecção com luz solar é o grau de radiação solar incidente. Segundo Zapp et al (1987 apud DANIEL et al, 2001), é necessário um mínimo de duas horas de exposição a $600 \mathrm{~W} \cdot \mathrm{m}^{-2}$ de radiação solar global direta, para que ocorra efetivo decaimento microbiano.

A ação microbicida da luz solar sobre os micro-organismos se deve principalmente aos efeitos da radiação UV-A, que chega à superfície terrestre e à radiação infravermelha. A primeira atinge os

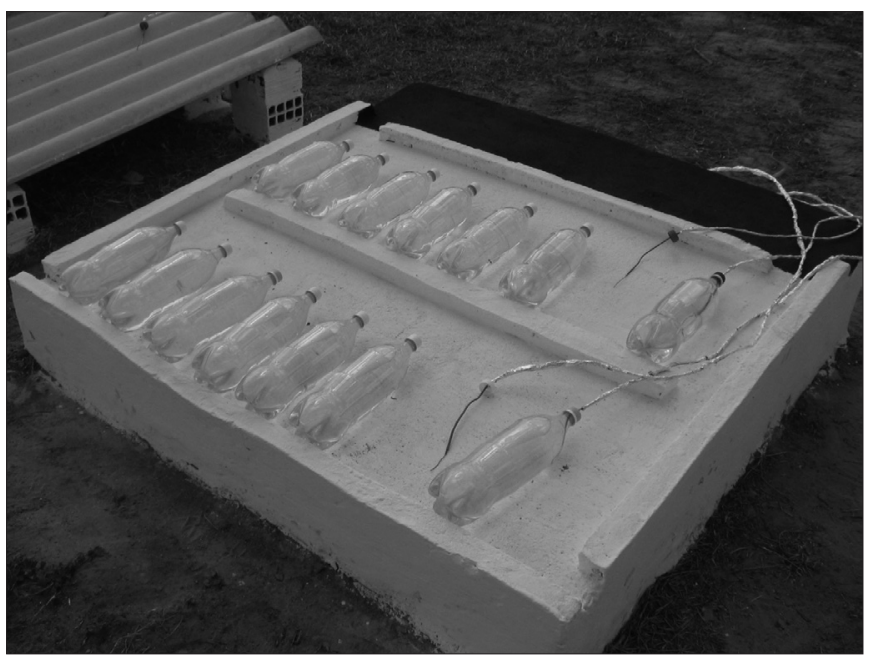

Figura 1 - Bancada de exposição das garrafas ácidos nucleicos e promove reações fotoquímicas de efeito microbicida, inativando vírus, bactérias, cistos de protozoários e ovos de helmintos, ao causar alterações na molécula de DNA (formação de dímeros de citosina, guanina e principalmente timina, que interrompem a duplicação da dupla hélice do DNA) (DANIEL et al, 2001). A segunda eleva a temperatura da água. O efeito sinérgico de ambas pode gerar condições ótimas para a desinfecção (BRANDÃO et al, 2000).

Diversos autores citam que o efeito bactericida da radiação solar na água depende do nível de oxigênio dissolvido (CURTIS et al, 1992; GOURMELON et al, 1994; REED, 1997 apud KEHOE, 2001). O oxigênio molecular reage com a luz solar gerando radicais livres hiperativos como superóxidos, hidroxilas e outros compostos oxidantes e tóxicos, como peróxidos que destroem estruturas básicas das células, em especial as membranas celulares e inibem atividades enzimáticas, causando a morte de micro-organismos procarióticos e eucarióticos

Segundo Meyer e Reed (2001), algumas espécies de bactérias presentes nas fezes possuem resistência à inativação pela radiação solar na ausência de oxigênio. Em consequência, para a aplicação da desinfecção solar em batelada usando garrafas PET, é recomendada a aeração da água por agitação manual das garrafas. Kehoe et al (2001) sugerem encher a garrafa até $2 / 3$ de sua capacidade, agitála durante um minuto para garantir altas concentrações iniciais de oxigênio dissolvido, completar o restante da garrafa e, então, expôla à radiação solar.

O presente trabalho apresenta resultados sobre a eficiência da desinfecção solar de água avaliando-se o efeito da incorporação de oxigênio dissolvido por agitação manual de garrafas PET

\section{Metodologia}

A pesquisa foi realizada no Estado do Ceará, nordeste do Brasil, região tropical de coordenadas 246'30" e 7052'15" de latitude sul e $37^{\circ} 14^{\prime} 54^{\prime \prime}$ e $41^{\circ} 24^{\prime} 45^{\prime \prime}$ de longitude ocidental.

O experimento foi montado na Estação Climatológica do Departamento de Engenharia Agrícola da Universidade Federal do Ceará (UFC). Foram construídas superfícies de concreto (1,50 $\mathrm{m}$ de comprimento por $1,50 \mathrm{~m}$ de largura) com inclinação de $4^{\circ}$, referente à latitude do local, e apontadas para o norte, onde as garrafas com a água a ser desinfetada ficaram expostas ao sol (Figura 1).

\section{Preparo da água contaminada}

Água proveniente de um poço com profundidade de $49 \mathrm{~m}$, nível estático de 23 m, nível dinâmico de $43 \mathrm{~m}$ e vazão de 4.200L.h-1 ${ }^{-1}$ foi contaminada com esgoto doméstico coletado por meio de baldes e cordas em um poço de visita no campus da UFC, com o intuito de 
preparar amostras com concentrações iniciais de coliformes termotolerantes superiores a $10^{5} \mathrm{NMP}$ por $100 \mathrm{~mL}$. Para alcançar tais concentrações, foram preparadas diluições de água na proporção de 0,5 L de esgoto bruto para $20 \mathrm{~L}$ de água. Essas amostras foram preparadas momentos antes de cada teste.

\section{Preparo, agitação e exposição das garrafas}

Para cada ensaio foram utilizadas 14 garrafas tipo PET (terifitalato de polietileno) transparentes de $2 \mathrm{~L}$, das quais seis foram agitadas manualmente durante um período de 30 segundos cada, seis não foram agitadas e duas foram usadas para controle no escuro.

O procedimento de enchimento das garrafas com a água sob teste foi o seguinte: as seis garrafas a serem arejadas foram preenchidas com a água contaminada até $2 / 3$ da sua capacidade e agitadas manualmente durante um minuto. Logo depois, completou-se o volume da garrafa até o gargalo com a mesma água; as garrafas sem agitação foram preenchidas de uma vez até o gargalo com a água sob estudo; as duas garrafas controle, sem agitação, foram cobertas completamente com papel alumínio para evitar a penetração da luz solar. As 12 primeiras garrafas foram expostas à radiação solar sobre a superfície de concreto pintado de branco (Figura 1). As duas garrafas controle foram mantidas em ambiente seco e arejado, sala escura do departamento de engenharia agrícola, sem exposição direta à radiação solar, com temperatura ambiente entre 28 e $33^{\circ} \mathrm{C}$.

Foram realizadas três baterias de ensaio totalizando 42 amostras: 36 de garrafas expostas ao sol (18 com agitação e 18 sem agitação) e 6 amostras controle.

Cada teste foi realizado no período entre $9 \mathrm{~h}$ e $15 \mathrm{~h}$, por ser esse o horário de maior insolação. A cada hora (uma, duas, três, quatro, cinco, seis horas), duas garrafas, uma com agitação prévia e outra não agitada, eram retiradas do sol. Para as análises físico-químicas e bacteriológicas foram utilizados aproximadamente $350 \mathrm{~mL}$ do volume total de cada garrafa (2 L). As análises bacteriológicas foram feitas em duplicata, com o propósito de detectar e/ou evitar possíveis erros analíticos laboratoriais

\section{Parâmetros analisados}

Em cada amostra de cada bateria de ensaio, foram analisados os seguintes parâmetros: turbidez (Espectrofotômetro marca HACH, modelo DR/2000), cor (Espectrofotômetro marca HACH, modelo DR/2000), pH (Potenciômetro marca MICRONAL, modelo B474), oxigênio dissolvido (sonda YSI-55), temperatura da água (sonda YSI55), concentração de coliformes termotolerantes (técnica de tubos múltiplos, Meio Al - APHA, 1998).

Dados meteorológicos (radiação solar e temperatura do ar) foram coletados a cada trinta minutos pela estação climatológica e armazenados no datalogger (Campbell Scientific, Inc, modelo: CR 10X).

\section{Cálculo do decaimento bacteriano}

A taxa de mortalidade bacteriana foi estimada de acordo com a lei de Chick (Equação 1) (VON SPERLING, 1996).

$\mathrm{N}=\mathrm{No}^{-\mathrm{e}_{\mathrm{k}} \cdot \mathrm{t}}$

Equação 1

Em que:

$\mathrm{N}$ : concentração de coliformes termotolerantes no tempo $\mathrm{t}$ (NMP.100 $\mathrm{mL}^{-1}$ );

No: concentração inicial de coliformes termotolerantes (NMP.100 mL-1); $k_{\mathrm{b}}=$ constante de inativação $\left(\mathrm{d}^{-1}\right)$;

$\mathrm{t}=$ tempo $(\mathrm{h})$.

Para a determinação da constante de decaimento bacteriano $k_{\mathrm{b}}$ foi utilizado o método dos mínimos quadrados, de Reed-Theriault (VON SPERLING, 1996)

\section{Análises estatísticas}

As ferramentas computacionais usadas foram: "STATDISK 9.1" $9^{\text {th }}$ e Statistical package for the social sciences (SPSS) versão 10. Foi aplicado o teste de hipótese de comparação das médias entre duas amostras independentes (razão $t$ de Student).

\section{Resultados}

A Tabela 1 apresenta a qualidade inicial das águas de poço inoculadas com esgoto e usadas nos três ensaios, antes da exposição ao sol.

Em todas as amostras, a turbidez inicial foi inferior a $30 \mathrm{uT}$, limite máximo recomendado para a técnica de desinfecção solar (WEGELIN et al, 1994; SOMMER et al, 1997).

Tabela 1 - Parâmetros físicos e microbiológicos das águas inoculadas com esgoto antes da exposição ao sol para os três dias de ensaio (Fortaleza, 2005)

\begin{tabular}{|c|c|c|c|c|}
\hline Data de ensaio & Turbidez (uT) & Cor (uH) & $\mathrm{pH}$ & $\begin{array}{l}\text { Coliformes termotolerantes } \\
\text { (NMP/IOO mL) }\end{array}$ \\
\hline 22/nov/05 & 6,5 & 39,5 & 7,54 & $2,05 E+06$ \\
\hline 6/dez/05 & 6,0 & 30,5 & 7,40 & $1,95 E+06$ \\
\hline 8/dez/05 & 1,0 & 11,0 & 7,62 & $2,07 \mathrm{E}+06$ \\
\hline
\end{tabular}




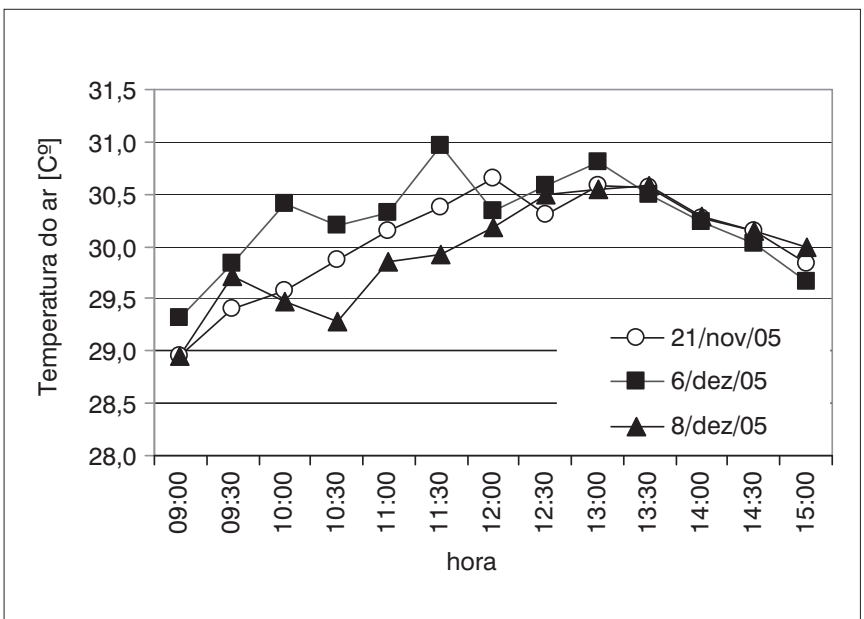

Figura 2 - Variação da temperatura do $\operatorname{ar}\left({ }^{\circ} \mathrm{C}\right)$ durante o tempo de exposição ao sol das amostras de água em garrafas PET (Fortaleza, 2005)

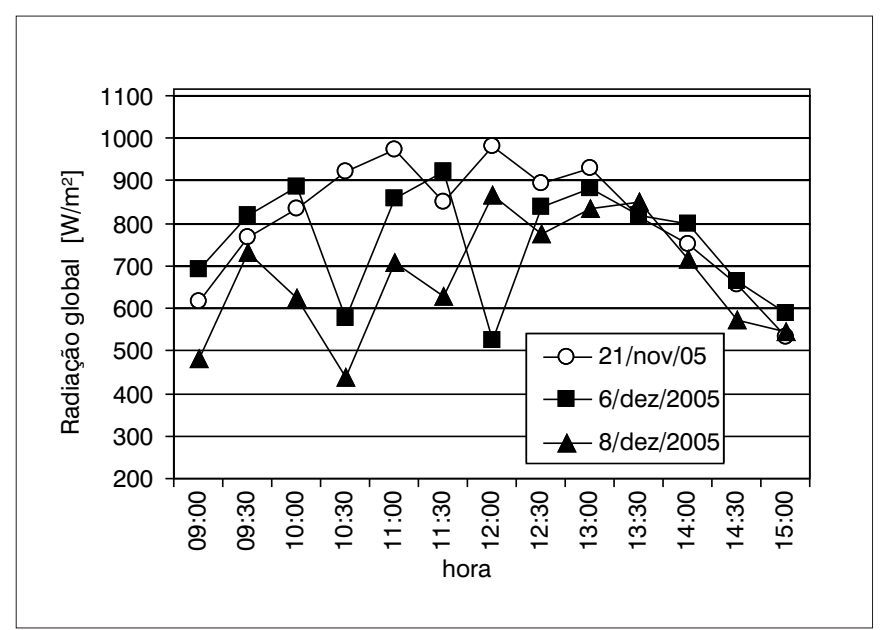

Figura 3 - Variação da intensidade de radiação solar $\left(\mathrm{W}^{\mathrm{m}} \mathrm{m}^{-2}\right)$ durante o tempo de exposição das amostras de água em garrafas PET (Fortaleza, 2005)

Concomitante à coleta das amostras, foram registrados parâmetros meteorológicos referentes aos três dias de ensaio (Tabela 2, Figuras 2 e 3). A Tabela 2 mostra que em todos os dias de ensaio houve mais de dez horas de brilho no período diurno.

A Figura 2 mostra que houve pequena variação horária da temperatura do ar durante os dias de ensaio, com valor médio aproximado de $30^{\circ} \mathrm{C}$, valor máximo de $31^{\circ} \mathrm{C}$ e mínimo de $29^{\circ} \mathrm{C}$.

A radiação solar global foi superior a $500 \mathrm{~W} \cdot \mathrm{m}^{-2}$ na maioria das horas de duração do experimento, valor considerado limite mínimo necessário para desinfecção eficiente com luz solar (SOMMER et al, 1997). Predominaram valores entre 600 e $800 \mathrm{~W} \cdot \mathrm{m}^{-2}$, sendo que o maior valor (981 W.m-2) ocorreu às 12 horas do dia 21 de novembro (Figura 3).

A Figura 4 apresenta o comportamento da concentração de oxigênio dissolvido nas amostras de água agitadas e não agitadas ao longo das seis horas de exposição.

Observa-se que a concentração inicial de oxigênio dissolvido nas garrafas agitadas foi de $6,61 \mathrm{mg} / \mathrm{L}$ e nas não agitadas de 5,56 mg/L,

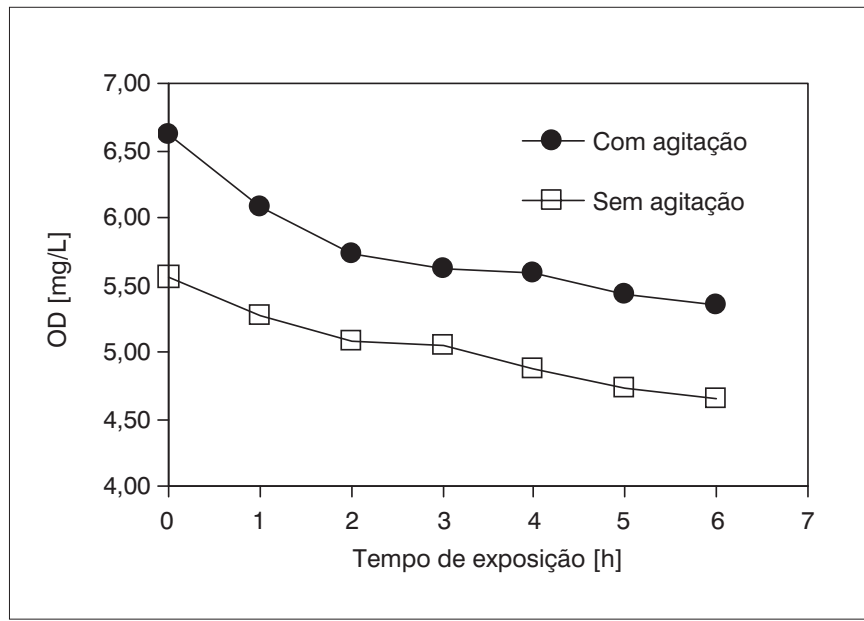

Figura 4 - Concentração média de oxigênio dissolvido das amostras de água em garrafas PET com agitação e sem agitação em função do tempo de exposição (Fortaleza, 2005)

Tabela 2 - Dados de insolação da Estação Meteorológica da UFC (Fortaleza, 2005)

\begin{tabular}{lc} 
Data & Horas de brilho do período diurno $[\mathrm{h}]$ \\
\hline 22/nov/05 & 11,2 \\
\hline 6/dez/05 & 11,2 \\
\hline 8/dez/05 & 10,0
\end{tabular}

havendo diferença de 1,05 mg/L. No decorrer das seis horas de exposição, a diferença foi, em média, de apenas 0,75 mg/L, mas estatisticamente significativa $(\mathrm{p}<0,05)$.

As diferenças encontradas por Meyer e Reed (2001) foram em média de 2,0 mg/L e superiores em 167\% às obtidas no presente estudo. Destaca-se que as circunstâncias experimentais foram distintas: no experimento de Meyer e Reed (2001) foram utilizadas amostras agitadas durante cinco minutos antes da exposição ao sol e amostras desoxigenadas por nitrogênio. Também não houve diminuição da concentração de oxigênio dissolvido ao longo do tempo de exposição, porque as amostras agitadas eram submetidas à agitação manual de hora em hora.

Pela análise de regressão dos dados de oxigênio dissolvido com temperatura da água para os dois procedimentos, observou-se forte correlação $\left(R^{2}=0,9784\right.$ nas amostras com agitação e $R^{2}=0,926$ nas amostras sem agitação) entre as variáveis (Figura 5).

O coeficiente de decaimento de oxigênio dissolvido ( $\mathrm{k}$ ) das amostras de água agitadas $\left(0,1249 \mathrm{~h}^{-1}\right)$ foi 1,5 vezes superior às amostras de água sem agitação $\left(0,0825 \mathrm{~h}^{-1}\right.$ considerando-se que devido à agitação manual, a concentração inicial de OD nas amostras agitadas foi $16 \%$ superior às amostras não-agitadas (Figura 5).

Resultados semelhantes de taxas médias de decaimento de oxigênio dissolvido foram evidenciados por Kehoe et al (2001), sendo que nas amostras agitadas o oxigênio dissolvido decresceu duas vezes mais rapidamente do que nas amostras não agitadas, com valores de $\mathrm{k}$ iguais a $0,103 \mathrm{~h}^{-1}$, e de $0,053 \mathrm{~h}^{-1}$, respectivamente. 
Tabela 3 - Eficiência de inativação solar de coliformes termotolerantes em garrafas PET com amostras de água com e sem agitação (valores médios e desvio padrão de três testes) (Fortaleza, 2005)

\begin{tabular}{|c|c|c|c|c|c|c|}
\hline \multirow[b]{2}{*}{ Tempo } & \multicolumn{3}{|c|}{ Sem agitação } & \multicolumn{3}{|c|}{ Com agitação } \\
\hline & $\begin{array}{l}\text { Coliformes } \\
\text { termotolerantes } \\
(\mathrm{NMP} / 100 \mathrm{~mL})\end{array}$ & $\begin{array}{c}\text { Eficiência } \\
\text { (Log10) }\end{array}$ & $\begin{array}{l}\text { Desvio Padrão } \\
\text { (Log10) }\end{array}$ & $\begin{array}{l}\text { Coliformes } \\
\text { termotolerantes } \\
\text { (NMP/100 mL) }\end{array}$ & $\begin{array}{c}\text { Eficiência } \\
\text { (Log10) }\end{array}$ & $\begin{array}{l}\text { Desvio Padrão } \\
\text { (Log10) }\end{array}$ \\
\hline 0 & $1,03 E+06$ & 0,000 & 0,49 & $1,03 E+06$ & 0,000 & 0,49 \\
\hline 1 & $2,66 \mathrm{E}+04$ & 1,588 & 0,82 & $2,87 E+04$ & 1,555 & 0,57 \\
\hline 2 & $1,15 E+03$ & 2,952 & 0,51 & $9,79 \mathrm{E}+02$ & 3,022 & 0,56 \\
\hline 3 & $1,88 \mathrm{E}+02$ & 3,739 & 0,73 & $1,25 E+02$ & 3,916 & 0,39 \\
\hline 4 & $9,69 E+01$ & 4,027 & 0,80 & $4,62 E+01$ & 4,348 & 0,79 \\
\hline 5 & $3,27 E+01$ & 4,498 & 0,34 & $2,30 E+01$ & 4,651 & 1,35 \\
\hline 6 & $6,67 E+01$ & 4,189 & 1,35 & $2,60 E+01$ & 4,598 & 0,77 \\
\hline
\end{tabular}

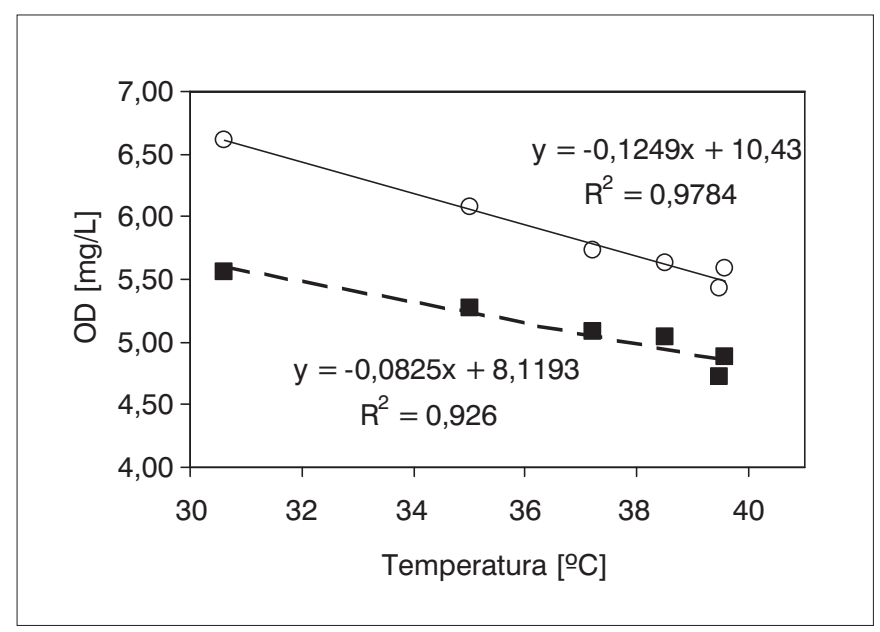

Figura 5 - Regressão linear dos valores de oxigênio dissolvido em função da temperatura para amostras em garrafas PET agitadas (०) e não agitadas (匹) (Fortaleza, 2005)

A Tabela 3 apresenta as eficiências médias de inativação de coliformes termotolerantes em amostras com agitação e sem agitação. Observa-se que a partir da terceira hora de exposição ao sol houve decaimento superior a $2 \log$ nos dois procedimentos em estudo. Ao final das seis horas de exposição, essa eficiência foi superior a $4 \log$.

Os valores de desvio padrão de coliformes termotolerantes não apresentaram grande variabilidade comum em contagens bacteriana. Os maiores valores de desvio padrão, 1,35 para a sexta hora de exposição nas amostras com agitação e quinta hora nas amostras sem agitação (Tabela 3), devem-se ao fato de que nesses tempos um dos três testes apresentou inativação total de coliformes termotolerantes.

Nas amostras controle, sem exposição ao sol e preservadas à temperatura ambiente, observou-se um decréscimo de $85 \%$ de coliformes termotolerantes nas três primeiras horas e aparente recrescimento ao final das seis horas (Figura 6).

As curvas de decaimento de coliformes termotolerantes nas amostras com e sem agitação mostram-se praticamente sobrepostas, indicando eficiências similares de desinfecção nas amostras com e

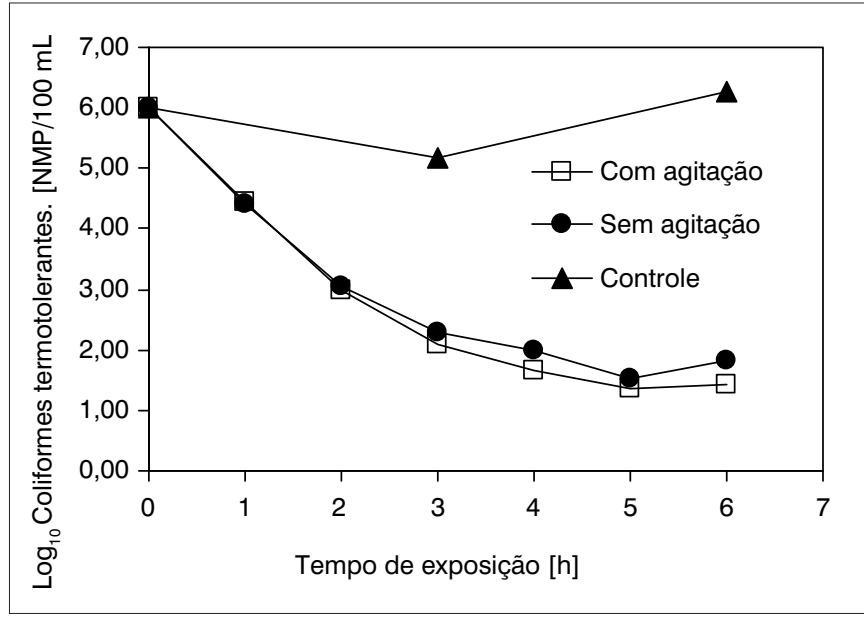

Figura 6 - Variação das concentrações médias de coliformes termotolerantes ao longo de seis horas de exposição ao sol em amostras de águas em garrafas PET agitadas, não agitadas e amostras controle. Fortaleza, 2005

sem agitação. Isso também se expressa nas constantes de decaimento bacteriano, com valor de $\mathrm{k}_{\mathrm{b}}$ de 0,3132 e 0,2837, respectivamente para as amostras agitadas e não agitadas.

A um nível de confiança de 95\%, não houve diferença significativa na eficiência de inativação de coliformes termotolerantes entre os dois métodos estudados, com e sem agitação ( $p>0,05)$.

\section{Conclusões}

A desinfecção por luz solar de água acondicionada em garrafas PET mostrou o potencial de inativação de coliformes termotolerantes de até 4 unidades logarítmicas, em amostras com concentrações iniciais superiores a $10^{5} \mathrm{NMP}$ por $100 \mathrm{~mL}$.

Entretanto, esse potencial de inativação deve ser confirmado em amostras com concentrações mais baixas de bactérias do grupo coliforme.

Por fim, os resultados não indicaram ganho de eficiência com a agitação prévia das amostras, sugerindo que esse procedimento possa ser dispensável. 


\section{Referências}

ACRA, A.; RAFFOUL, Z.; KARAHAGOPIAN, Y. Solar disinfection of drinking water and oral rehydratation solution: guidelines for households application in developing countries. Beirut: American University of Beirut/ UNICEF, 1984

APHA/AWWA/WEF. Standard methods for the examination of water and wastewater. 20 ed. Washington, DC: APHA, 1998.

BRANDÃO, C.C.S. et al. Avaliação da desinfecção solar na região centro-oeste do Brasil usando diferentes organismos indicadores de contaminação. In: XXVII CONGRESSO INTERAMERICANO DE ENGENHARIA SANITÁRIA E AMBIENTAL, ABES, Rio de Janeiro, 2000.

DANIEL, L.A. et al. Processos de desinfecção e desinfetantes alternativos na produção de água potável. Rio de Janeiro: RiMa/ABES, 2001.

KEHOE, S.C. et al. Effect of agitation, turbidity, aluminum foil reflectors and container volume on the inactivation efficiency of batch-process solar disinfectors. Water Research, v. 35, n. 4, p. 1061-1065, 2001.

MEYER, V.; REED, R.H. SOLAR disinfection of coliform bacteria in handdrawn drinking water. Water SA. v. 27, n. 1, 2001. [On-line]. Disponível em:
http://www.wrc.org.za/archives/watersa\%20archive/2001/January/1361. pdf Acesso em: 21 jul. 2009.

REED, R.H. Innovations in solar water treatment. In: $23^{\text {rd }}$ WEDC CONFERENCE WATER AND SANITATION FOR ALL: PARTNERSHIPS AND INNOVATIONS. Durban, South Africa, 1997.

SOMMER, B. et al. SODIS: an emerging water treatment process. Journal of Water Supply: Research and Technology - Aqua, v. 46, n. 3, p. 127-137, 1997.

VON SPERLING, M. Introdução à qualidade das águas e ao tratamento de esgotos. 2. ed. Belo Horizonte: UFMG, 1996.

WEGELIN, M. et al. Solar water disinfection: scope of the process and analysis of radiation experiments. Journal of Water Supply: Research and Technology - Aqua, v. 43, n. 3, p. 154-159, 1994.

WORLD HEALTH ORGANIZATION (WHO); UNITED NATIONS CHILDREN'S FUND (UNICEF). Global water supply and sanitation assessment 2000 report. Geneva, Suíça. [On-line]. Disponível em: http://www.who.int/water_sanitation_health/monitoring/globalassess/en/ index.html. Acesso em: 16 jul. 2009. 